\title{
Osteoporoz Tanısı ile Oral Bisfosfonat Kullanan Hastada Çene Osteonekrozu Gelişimi: Olgu Sunumu
}

\author{
Development of Osteonecrosis of the Jaw in a Patient Receiving Oral Bisphosphonates \\ for Osteoporosis: A Case Report
}

Sina Esmaeilzadeh, Ekin ilke Şen, Tuğba Aydın, Bahar Dernek, Nurten Eskiyurt

istanbul Üniversitesi İstanbul Tıp Fakültesi, Fiziksel Tıp ve Rehabilitasyon Anabilim Dalı, i̇stanbul, Türkiye

\section{Özet}

Bisfosfonatların ciddi yan etkilerinden olan bisfosfonatlara bağlı çene osteonekrozu (BRONJ), osteoporoz tedavisinde bisfosfonatların yaygın kullanımı nedeniyle giderek artan klinik önem taşımaktadır. BRONJ tedavisinde güncel tedavi yöntemlerinin sınırlı olduğu göz önüne alındığında risk faktörlerinin değerlendirilmesi BRONJ gelişiminin önlenmesinde ve uygun medikal tedavi seçiminin belirlenmesinde önemli rol oynamaktadır. Bu olgu sunumu eşliğinde oral bisfosfonat kullanımı sonrası görülen BRONJ'un tanısı, patogenezi ve risk faktörleri gözden geçirilmiştir. (Türk Osteoporoz Dergisi 2014;20: 75-80)

Anahtar kelimeler: Oral bisfosfonat, osteoporoz, çene osteonekrozu

\section{Summary}

Clinical importance of the bisphosphonate-related osteonecrosis of the jaw (BRONJ) which is one of the serious side effects of bisphosphonates is increasing due to the widespread use of bisphosphonates in the treatment of osteoporosis. Since current treatment options for the BRONJ are limited, evaluation of the risk factors is very important in preventing the development of BRONJ and determining the appropriate medication in osteoporosis management. In the present case report, diagnosis, pathogenesis and risk factors of the BORNJ which is observed following bisphosphonate use were reviewed. (Turkish Journal of Osteoporosis 2014;20: 75-80)

Key words: Oral bisphosphonates, osteoporosis, osteonecrosis of the jaw

\section{Giriş}

Günümüzde, osteoporoz ve osteoporoza bağlı kırıklar gittikçe artan, önemli derecede sosyoekonomik yüke neden olan bir sağlık problemi haline gelmiştir $(1,2)$. Osteoporoz tedavisinde önemli yeri olan bisfosfonatların kullanımı ise giderek artmaktadır. Uzun süreli bisfosfonat tedavisi alan popülasyonun artışı göz önüne alındığında olgu sunumumuzdaki amacımız bisfosfonatların nadir görülen ancak ciddi yan etkilerinden olan bisfosfonatlara bağlı çene osteonekrozunun (BRONJ) tanısı, patogenezi ve risk faktörlerini gözden geçirerek klinik bakış açıs sağlamaktır

\section{Olgu}

Altmış dokuz yaşındaki bayan hasta, Şubat 2011'de İstanbul Üniversitesi İstanbul Tıp Fakültesi, Fiziksel Tıp ve Rehabilitasyon Anabilim Dalı, Osteoporoz Tanı ve Tedavi Ünitesi'ne BRONJ tanısı ile başvurdu. Alınan anamnezde menarş yaşı 13 olan hasta 40 yaşında doğal menopoza girmişti. Bu süre içinde 5 çocuk doğuran hasta 12 sene önce tiroidektomi geçirmişti. Hasta hipotroidi nedeni ile levotiroksin 100 mcg tablet günde bir oral kullanmakta idi. Düşme ve kırık öyküsü olmayan hastanın ailesinde de kırık mevcut değildi. Hastanın önceki ilaç raporlarından edinilen bilgiye göre, osteoporoz tanısı ile 2007 yllında strontium ranelate 2 gr günde bir oral, 2008'de risedronat 35 mg haftada bir oral, 2009 ve 2010 yıllarında ise ibandronat 150 mg ayda bir oral kullanıldığı öğrenildi. Hasta, 2007-2011 yılları arasında düzensiz bir biçimde kalsiyum (600 $\mathrm{mg} / \mathrm{d}$ ) ve $\mathrm{D}$ vitamini (400 iÜ/d) kullanmıştı. Hastanın üçüncü molar dişi başvuru tarihinden yaklaşık bir sene önce çekilmişti. Hastanın ağzındaki yara kapanmayınca tekrar çekilen panoramik radyografide sol mandibula posteriorunda osteonekroz tespit edilmişti. 22.10.2010 tarihinde istenen manyetik rezonans görüntülemesinde yine aynı bölgede medullar trabeküler ödem

Yazışma Adresi/Address for Correspondence: Dr. Sina Esmaeilzadeh, İstanbul Üniversitesi İstanbul Tıp Fakültesi, Fiziksel Tıp ve Rehabilitasyon Anabilim Dalı, İstanbul, Türkiye Tel.: +90 21241420 00/12850 E-posta: sinabox@gmail.com Geliş Tarihi/Received: 24.04.2014 Kabul Tarihi/Accepted: 26.05 .2014

Türk Osteoporoz Dergisi, Galenos Yayınevi tarafindan basılmıştır. / Turkish Journal of Osteoporosis, published by Galenos Publishing. 
ve çevre yumuşak dokularda ödematöz sinyal değişiklikleri izlenmiş olup bu bulgu yumuşak doku enfeksiyonunun eşlik ettiği osteomiyelit olarak düşünülmüştü. Bu nedenle hasta uzun süreden beri amoksisilin-klavulanik asit ile beraber metronidazol tedavisi kullanmaktaydı. Ağız içi yarası gerekli cerrahi müdahalelere rağmen bir türlü kapanmayan hastaya, diş çekimi sonrası osteomiyelit ve BRONJ tanıları konularak medikal tedavi değişikliği için tarafımıza yönlendirilmişti. Hastaya yapılan tetkiklerin sonucu Tablo 1'de verilmiştir. Hastanın tedavisi mevcut durumlar göz önüne alınarak raloksifen 60 mg günde bir oral ve kalsiyum (1000 mg/gün) ve D vitamini (800 iÜ/gün) olarak değişsirildi.

\section{BRONJ}

Bisfosfonatlar osteoporoz, multipl myelom, Paget hastalığı ve malignite hiperkalsemisi gibi kalsiyum metabolizması bozukluklarında kullanılan antiosteoklastik ve antirezorptif ajanlardır. Kemik morfolojisini iyileştirirken kemik yıkımı ve patolojik kırıkların önlenmesinde, metastatik kemik hastalıkları ile ilişkili ağrının azaltılarak kemik rezorpsiyonunun yavaşlatılmasında

\section{Tablo 1. Tetkik sonuçları (Şubat 2011)}

\begin{tabular}{|c|c|c|c|}
\hline & Sonuç & Birim & $\begin{array}{l}\text { Normal } \\
\text { Değer }\end{array}$ \\
\hline \multicolumn{4}{|l|}{ Serumda } \\
\hline Kalsiyum & 9,8 & $\mathrm{mg} / \mathrm{dl}$ & $8,5-10,5$ \\
\hline Fosfor & 2,7 & $\mathrm{mg} / \mathrm{dl}$ & $2,7-4,5$ \\
\hline Alkalen fosfataz & 136 & $U / L$ & $90-260$ \\
\hline Parathormon & 48 & $\mathrm{pg} / \mathrm{ml}$ & $15-65$ \\
\hline Tiroid stimülan hormon & 11,48 & $\mathrm{mlU} / \mathrm{L}$ & $0,27-4,2$ \\
\hline Serbest T4 & 15,1 & $\mathrm{pmol} / \mathrm{L}$ & $12-22$ \\
\hline 25-OH Vitamin D & 27,1 & $\mathrm{ng} / \mathrm{ml}$ & $30-80$ \\
\hline Osteokalsin & $<2,00$ & $\mathrm{ng} / \mathrm{ml}$ & $<2,0-22$ \\
\hline CTx & 0,146 & $\mathrm{ng} / \mathrm{ml}$ & \\
\hline
\end{tabular}

\section{Saatlik İdrarda}

\begin{tabular}{|l|l|l|l|}
\hline Kalsiyum & 3,83 & $\mathrm{mg} / \mathrm{dl}$ & \\
\hline Fosfor & 24,3 & $\mathrm{mg} / \mathrm{dl}$ & \\
\hline
\end{tabular}

\section{Kemik Mineral Yoğunluk (DXA, LUNAR)}

\begin{tabular}{|l|l|l|l|}
\hline Alan & BMD & T-skoru & \\
\hline L1 & 0,894 & $-2,0$ & \\
\hline L2 & 0,876 & $-2,7$ & \\
\hline L3 & 0,873 & $-2,7$ & \\
\hline L4 & 0,749 & $-3,8$ & \\
\hline L1-L4 & 0,844 & $-2,8$ & \\
\hline Femur Boynu & 0,734 & $-2,1$ & \\
\hline Femur Trokanter & 0,709 & $-0,7$ & \\
\hline Femur Toplam & 0,805 & $-1,6$ & \\
\hline $\begin{array}{l}\text { Tip 1 Kollajen C-terminal Telopeptid, CTx; Dual-energy X-ray absorptiometry, } \\
\text { DXA }\end{array}$ & \multicolumn{5}{l|}{} \\
\hline
\end{tabular}

etkilidir $(3,4)$. Oral olarak kullanılan bisfosfonatlar oral kavitede tekrarlayan ülserler ve büller, eroziv özojajit, özofagial stenoz, üveit, gastrik ülserasyon ve abdominal ağrıya neden olabilir (5). Bununla beraber bisfosfonatlarla tedavi edilen hastalarda daha nadir olarak dental girişimleri de içeren lokal minör travmayı takiben BRONJ olarak adlandırılan çene veya maksiler kemikte osteonekroz gelişimi görülebilir (3).

illk defa 2003 yılında Marx ve ark. tarafından bisfosfonatların osteonekroz ile ilişkili olduğu anlaşılmış ve BRONJ'un ilk klinik tanımlaması yapıımıştır (6). BRONJ, 2007'de "American Association of Oral and Maxillofacial Surgeons (AAOMS)" ve "American Society for Bone and Mineral Research" tarafından bisfosfonat kullanan veya geçmişte kullanmış olan hastalarda, radyoterapi öyküsü olmaksızın sekiz haftadan fazla süredir mevcut olan maksillofasyal bölgede ekspoze kemik alanı olarak tanımlanmıştır (7). Bununla beraber evreleme göz önüne alındığında (Tablo 2) evre $0^{\prime}$ da ekspoze kemiğin olmaması nedeniyle daha sonra BRONJ tanımlaması "ekspoze veya nekrotik kemik" olarak güncellenmiştir (8). BRONJ oluşumunun klasik belirtisi nekrotik çene kemiğinin oluşumudur. Bunun yanı sıra diş veya kemikte ağrı, süpürasyon, şişlik, çene kemiği ile ilişkili sinüs ve fistül oluşumu, dişte mobilite, trismus, yumuşak doku ülserasyonları, mandibular deformite ve kemikte sekestrasyon varlığı BRONJ ile ilişkili diğer olası klinik belirtiler ve semptomlardır. Bu belirtiler ışığında diğer intraoral durumların ayırıcı tanısı yapılmalıdır (3).

\section{BRONJ'un Etiyopatogenezi}

Etiyopatogenezi tam olarak anlaşılamayan BRONJ'un oluşumuna yönelik birçok mekanizma ortaya konulmuş ancak hiçbiri görülen makroskopik ve mikroskopik düzeydeki değişiklikleri tek başına açıklamada yeterli olmamıştır $(3,10)$. BRONJ'un patogenezi ile ilgili hipotezlerden kemiğin yeniden yapılanmasının baskılanması, anti-anjiogenik etkiler ve enfeksiyon en popüler teorilerdir (11). Bisfosfonatlar osteoklastik inhibisyon ile kemiğin yeniden yapılanmasını baskılayarak kemiğin iyileşme kapasitesini

\section{Tablo 2. Bisfosfonat ilişkili çene osteonekrozu için AAOMS evreleme sistemi (9)}

Risk Nekrotik kemik görülmeyen ancak oral veya intravenöz bisfosfonatlarla tedavi edilen hastalar

Evre $0 \quad$ Nekrotik kemik ile ilgili klinik bulgu yok ancak non-spesifik bulgular ve semptomlar mevcut

Evre 1 Enfeksiyon bulgusu yok, asemptomatik, ekspoze/ nekrotik kemik

Evre 2 Enfeksiyon ile ilişkili ekspoze/nekrotik kemik; pürülan akıntı ile beraber olan veya olmayan ekspoze kemikte ağrı ve eritem

Evre 3 Ağrı, enfeksiyon ile ilişkili ekspoze/nekrotik kemik ve eşlik eden bir veya daha fazlası: alveolar kemiğe uzanan patolojik fraktür ile sonuçlanan ekspoze ve nekrotik kemik, ekstraoral fistül, oral antral/oral nazal komünikasyon, inferior mandibulaya uzanan osteoliz veya sinüs

American Association of Oral and Maxillofacial Surgeons, AAOMS 
azaltmaktadır. Ancak yumuşak dokuda invivo olarak toksik etki oluşumu için yeterli konsantrasyonda bulunup bulunmadıkları net değildir (12). Son yayınlarda ise bisfosfonatların antianjiogenik etkilerinin BRONJ'un klinik özellikleri üzerinde etkili olduğu belirtilmektedir (3).

$\mathrm{Bu}$ olguda sunumunda oral bisfosfonat kullanım öyküsü olan hastada üçüncü molar diş çekimi sonrası gelişen çene osteonekrozu literatür eşliğinde tartışılacaktır.

\section{Tartışma}

BRONJ, bisfosfonatların nadir görülen fakat önemli ve beklenmeyen bir yan etkisidir (13). BRONJ oluşumu açısından riskli hastaların belirlenmesi ve bu risk faktörlerinin değerlendirilmesi BRONJ gelişiminin önlenmesinde ve uygun medikal tedavi seçiminin belirlenmesinde önem taşımaktadır. AAOMS tarafından belirlenen risk faktörleri arasında bisfosfonat ile ilgili faktörler, lokal risk faktörleri, demografik ve sistemik faktörler ile genetik faktörler yer almaktadır.

Bisfosfonatların etki gücü ve kullanım süresi gibi ilaçla ilgili faktörler BRONJ oluşumunda rol oynamaktadır (9). Klinikte antirezorptif ajanlar olarak kullanılan bisfosfonatlar nitrojen içermeyen ve nitrojen içeren bisfosfonatlar olarak sınıflanır. Nitrojen içermeyen bisfosfonatlar nitrojen içerenlere göre daha az güçlüdür. Nitrojen içeren bisfosfonatlar ise güçlüden zayıfa doğru zoledronat, risedronat, ibandronat, alendronat ve pamidronat şeklinde sıralanmaktadır. Osteoporoz tedavisinin yanı sıra malignitelerde olduğu gibi ciddi rezorpsiyon varlığında tercih edilen zoledronat ve risedronat gibi nitrojen içeren heterosiklik bisfosfonatların daha güçlü olduğu görülmektedir $(14,15)$.

BRONJ ilk olarak intravenöz bisfosfonat alan hastalarda tanımlanmıştır (6). Genellikle, nitrojen içeren intravenöz bisfosfonatlarla BRONJ oluşumu daha sık görülmektedir $(3,16)$. Intravenöz bisfosfonatlarla görülen BRONJ, bisfosfonatların spesifik tipi, tek veya çok sayıdaki bisfosfonatların eş zamanlı veya ardı sıra uygulanması aynı zamanda tedavinin süresine bağlı olarak \%0,0 ile \%28 arasında değişen farklı oranlarda belirtilmiştir (17-19). Oral bisfosfonat kullanan hastalarda BRONJ'un daha nadir olarak görüldüğü, yapılan çalışmalarda prevalansının \%0,01 ile \%0,1 arasında olduğu belirtilmiştir (20-22). Bununla beraber oral bisfosfonat kullananlarda BRONJ insidansı yapılan çalışmalarda farklılık göstermektedir $(23,24)$. Oral BRONJ olgularının intravenöz BRONJ olgularına göre daha sınırlı ve daha az ciddi olduğu bununla beraber nadir olgularda cerrahi rezeksiyon gerektiren geniş ve/veya dirençli olguların da bildirildiği görülmektedir (25). Yapılan çok merkezli bir çalışmada BRONJ oluşumunun en sık görüldüğü oral bisfosfonatların sırasıyla alendronat, risedronat, ibandronat ve klodronat olduğu bildirilmiştir (24). Diniz-Freitas ve ark.'nın çalışmasında ise 20 hastanın 16'sının alendronat, 4'ünün ise ibandronat kullandığı bildirilmiştir (26). Etki gücünün diğer nitrojen içeren oral formlara göre düşük olmasına rağmen alendronat ile ilişkili BRONJ oranının yüksek olmasının alendronatın sık reçete edilmesi, uzun süre kullanımı, yarılanma zamanı ve absorbsiyonu ile ilişkili faktörlere bağlanabileceği düşünülmektedir (27). Bizim olgumuzda alınan anamneze göre oral risedronat ve oral ibandronat kullanımı mevcut idi.

iki yıldan uzun süreli bisfosfonat kullanımı BRONJ için artmış risk ile ilişkili bulunmuştur (12). Oral bisfosfonat kullanım süresi çalışmalarda 0,3-15 yıl arasında değişkenlik göstermekle beraber genel olarak olgularda ortalama tedavi süresinin 3 yılı geçtiği ifade edilmiştir $(24,25,28)$. Bizim olgumuzda bisfosfonat kullanım süresinin 3 yıl olduğu saptanmıştır. Palaska ve ark.'nın çalışmasında BRONJ gelişen hastalarda ortalama oral bisfosfonat kullanım süresi 4,6 yıl, BRONJ oluşumuna kadar geçen ortalama minimum zaman 3 yıl olarak belirtilmiş, ilişkili komorbid durumları olan hastalarda erken başlangıç olduğu saptanmıştır. Zoledronat kullanımında ise bu periyodun 1,8 yıl olduğu görülmektedir (29). İntravenöz bisfosfonat kullanımında BRONJ gelişiminin hızlı olmasının bu ilaçların biyoyararlanımının daha yüksek olmasına ve kemikte daha hızlı birikmesine bağlı olduğu düşünülmektedir.

Diş çekimi, dental implant, periodontal cerrahi gibi dentoalveolar cerrahi prosedürler, eşlik eden oral hastalık ve kötü ağız hijyeni BRONJ için bilinen risk faktörleridir. Aynı zamanda bisfosfonatların oral mukozadaki keratinositlerin proliferasyonunu inhibe ettiği gösterilmiştir, bu nedenle ağıza uyumu iyi olmayan diş protezlerinin de oral mukoza yaralanmasına yol açarak bisfosfonat kullananlarda BRONJ riskini arttırdığı belirtilmiştir. Oral bisfosfonatlara bağlı oluşan BRONJ spontan veya daha sıklıkla kemiğe travma sonucu oluşabilir. Kemik yeniden yapılanmasına artmış ihtiyaç söz konusu olduğunda bisfosfonatlarla görülen inhibisyon, kemikte nekroz oluşumuna yatkınlık oluşturmaktadır $(12,26)$. Olgumuzda BRONJ oluşumu için risk faktörü olan yaklaşık bir sene önce üçüncü molar diş çekimi mevcut idi. Benzer şekilde yapılan çalışmalarda invaziv dental girişimlerin BRONJ oluşumu için risk faktörü olarak önem taşıdığı görülmektedir. Beninati ve ark.'nın çalışmasında \%61 hastada invaziv dental girişim öyküsü mevcutken, \%16 hastada travmatik bir olay saptanmamıştır (30). Oral bisfosfonatlar ile yapılan en geniş hasta sayısı olan çalışmalardan birinde osteoporoz veya osteopeni tedavisi için oral bisfosfonat (primer olarak alendronat) kullanan çene osteonekrozu görülen hastaların üçte birinde BRONJ spontan olarak görülürken, diğer hastalarda invaziv dental prosedürler sonrası izlenmiştir (27). O’Ryan ve ark.'nın 30 hastalık oral BRONJ serisinde diş çekimi sonrası BRONJ'un 17 hastada görüldüğü bildirilmiştir (25).

Villa ve ark.'nın çalışmasında osteoporozu olan ve bisfosfonat kullanan hastalarda özellikle periodontal hastalık veya abse gibi ağızda enfeksiyöz süreç varlığında mandibulada osteonekroz gelişebileceği belirtilmiştir. Aynı zamanda bisfosfonat tedavisi alanlarda diş çekimi sonrası BRONJ gelişme riskinin üç kat daha fazla olduğu saptanmıştır (31). Olgumuzda da diş çekimi sonrası uzun süre periodontal kapanmayan yara olduğu bilinmekte idi. BRONJ lokalizasyonu incelendiğinde yapılan çalışmalarda lezyonların mandibulada maksillaya göre daha sık görüldüğü 
bildirilmiştir (27,31). Benzer olarak olgumuzda mandibula posteriorunda osteonekroz olduğu görülmektedir.

Illeri yaşın BRONJ için risk faktörü olduğu bilinmektedir. Immunsupresyon, romatoid artrit, diabetes mellitus (DM), sigara kullanımı, obezite, diyaliz gibi bazı sistemik faktörlerin aynı zamanda glukokortikoid ve/veya hastalık modifiye edici ajanların (DMARDs) kullanımının da BRONJ riskini arttırdığı bildirilmiştir $(10,27,32,33)$. Olgumuzdaki 69 yaşında bayan hastada ise bilinen komorbid risk faktörü bulunmamaktadır. Benzer şekilde Otto ve ark.'nın çalışmasında oral bisfosfonatlarla ilişkili BRONJ tipik olarak 70 yaşlarında, oral cerrahi geçirmiş kadınlarda görülmüştür. Bazı hastalarda bilinen hiçbir risk faktörü bulunmamıştır (24). O'Ryan ve ark.'nın 30 hastalık oral BRONJ serisinde hastaların \%87'si bayan, yaş ortalaması 77 olarak bulunmuştur (25). Yaş ortalaması diğer oral BRONJ olgu serilerine benzerdir $(10,24,27,34)$. Olguların yarıdan fazlasında (\%57) komorbidite veya ilişkili ilaç kullanımı olduğu gösterilmiş; DM, kronik glukokortikoid ve/veya DMARDs tedavisini gerektiren sistemik enflamatuar hastalıklar BRONJ ile ilişkili en sık komorbiditeler olarak saptanmıştır. Aynı zamanda komorbiditleri olan hastalarda iyileşme oranının düşük olduğu ve iyileşme süresinin uzun olduğu gözlenmiştir (25).

BRONJ tedavisinde yakın zamanda kaydedilen ilerlemelere rağmen tüm güncel tedaviler sınırlı kalmaktadır. Bu nedenle bisfosfonat kullanan hastalarda spontan olarak veya dentoalveolar cerrahiyi takiben BRONJ gelişimi açısından riskli hastaların tahmin edilmesinde yararlı olabilecek biyokimyasal bir belirtecin olması önem taşımaktadır. Tip 1 Kollajen C-terminal Telopeptid'in (CTX) BRONJ riskinin tahmin edilmesinde kullanılabileceğini belirtmiştir (27). Serum CTx seviyesi kemik yeniden yapılanması ve rezorpsiyonunu ölçmek için kullanılan osteoklastik aktivitenin güvenilir bir belirtecidir. Artmış kemik döngüsü olan hastalarda CTx değeri artmış olarak saptanırken bisfosfonat gibi antirezorptif ilaç kullanımı sırasında seviyesinde azalma olmaktadır. Bisfosfonat tedavisi başlanacak hastalardan hastanın tedaviye yanıtının ve uyumunun izlenmesi açısından başlangıç CTx değerlerinin tedavi öncesi istenmesi önerilmektedir (13). Marx ve ark.'nın çalışmasında BRONJ'u olan 30 hastanın CTx değerleri retrospektif olarak değerlendirilmiş, 100 pg/ ml'nin altındaki değerlerde BRONJ riskinin yüksek olduğu 100 ile 150 pg/ml'nin altındaki değerlerde orta risk, 150 pg/ ml'nin üzerindeki değerlerde ise riskin minimal olduğu veya olmadığı belirtilmiştir (27). CTx düzeylerinin BRONJ gelişimi için belirleyici olmadığı, ancak 150-200 pg/ml'nin altındaki değerlerin "riskli aralık" olarak adlandırıldığı, oral cerrahi öncesi risk değerlendirilmesinde ve klinik karar aşamasında yardımcı olarak kullanılabileceği belirtilmiştir $(13,35,36)$. Bu bulguları destekler şekilde olgumuzun CTx düzeylerinin 150 pg/ml'nin altında olduğu görülmektedir. Bununla beraber BRONJ gelişiminin önceden tahmin edilmesinde CTx kullanımı konusunda net bir fikir birliğ bulunmamaktadır. BRONJ oluşumunun tahmin edilmesinde CTx'in rolünü değerlendiren $\mathrm{O}^{\prime}$ Connel ve ark.'nın çalışmasında oral cerrahiyi takiben BRONJ gelişimi için CTx' in belirleyici olmadığı gösterilmiştir (13). Kwon ve ark.'nın çalışmasında serum CTx değerleri ile BRONJ ciddiyeti arasında ilişki olduğu gösterilmiş, bununla beraber BRONJ oluşumunun tahmin edilmesinde CTx düzeylerinin etkili olmadığı öne sürülmüştür (37).

Oral veya intravenöz bisfosfonat tedavisi planlanan osteoporozlu hastalarda ağız hijyeni ve dental bakımın iyi olması durumunda tedaviye başlamadan önce dental muayene gerekmemektedir. iki yılın altında bisfosfonat kullanımı olan hastalarda dentoalveolar prosedürler sonrası BRONJ gelişim riskinin düşük olmasına rağmen antirezorptif tedaviye başlamadan önce mümkünse girişimsel dental tedavilerin tamamlanması önerilmektedir. Onkoloji hastalarında ise intravenöz bisfosfonatlara başlamadan önce dental değerlendirme yapılmalı ve dental invaziv prosedürler tamamlanmalıdır $(38,39)$.

Dental tedavi öncesi BRONJ gelişiminin önlenmesi için antirezorptif tedaviye ara verilmesi veya bekleme periyodları olması gerektiğine dair yeterli kanıt mevcut değildir. Bisfosfonatların kesilmesinin BRONJ gelişim riskini azaltmayabileceği bununla beraber osteoporoz tedavisinin sonuçları üzerinde olumsuz etkisi olabileceği belirtilmiştir. Hangi hastalarda kesin olarak BRONJ gelişeceğini belirleyen geçerli bir tanı yöntemi bulunmamaktadır. Ancak önemli risk faktörleri varlığında bisfosfonat tedavisinin kesilmesinin göz önüne alınmasının gerekebileceği belirtilmiş ve tartışılarak karar verilmesi önerilmiştir. Sigara kullanımının bırakılması, alkol alınımın sınıllanması, oral hijyenin sağlanması ve düzenli diş hekimi kontrolü BRONJ riskinin azaltılmasında uygulanabilecek optimal yaklaşımlardır. Sonuçta, bisfosfonat tedavisine devam edilmesinin yararları ve zararları bireysel olarak değerlendirilmeli ve hasta ile konuşularak karar verilmelidir (38-40).

Osteoporoz tedavisinde kullanılan bisfosfonatlarda pencere periyodu süresi tanımlanmamıştır. Onkoloji hastalarında bisfosfonat tedavisine başladıktan 6-36 ay içinde uygulanan dental girişimlerin BRONJ oluşum riskini azalttığı ancak riski tamamen ortadan kaldırmadığı belirtilmiş̧ir (41).

Uzun süre intravenöz bisfosfonat kullanan yerleşmiş BRONJ görülen olgularda klinik semptomların ve yeni osteonekroz bölgelerinin gelişim riskinin azaltılması açısından bisfosfonatların kesilmesinin yararlı olabileceği belirtilmiştir (42). BRONJ dışındaki dental problemlerde bisfosfonat tedavisine ara verilmesini destekleyen veri bulunmamaktadır. BRONJ dışında dental problemi olan bisfosfonat kullanan onkoloji hastalarında en az invaziv dental tedavi önerilmektedir. Diş çekimi veya diğer dental cerrahi gerekliliğinde yeterli veri olmamakla beraber cerrahi bölge iyileşene kadar bisfosfonat tedavisine ara verilmesinin göz önünde bulundurulması önerilmiştir. Hiperkalsemi gibi tedavinin devamının önem taşıdığı riskli olgularda bisfosfonatlara devam edilebileceği belirtilmiş̧ir (43). Antirezorptif tedavi kullanmakta olan aktif kronik periodontal hastalığı olan hastalarda cerrahi olmayan tedavi yöntemlerinin kullanılması ve 4-6 hafta aralıklarla takip edilmesi önerilmektedir. Bununla beraber cerrahi prosedürlerin bu hastalarda kontraendike olduğunu söylemek mümkün değildir (39).

BRONJ tedavisi sırasında antirezorptif ilaçların kesilmesini destekleyen çalışmalar olmakla beraber BRONJ'un önlenmesinde tedaviye ara verilmesinin etkinliğini gösteren yeterli veri bulunmamaktadır $(39,44)$. Bununla beraber BRONJ 
tedavisinde nitrojen içeren bisfosfonatların nitrojen içermeyen bisfosfonatlarla değiştirilmesi veya bisfosfonatların kesilmesinin göz önünde bulundurulması önerilmektedir (41). Bizim olgumuzda da benzer şekilde hastanın kullanmakta olduğu bisfosfonat tedavisine ara verilmiştir.

Özetle, kemik yeniden yapılanması ve bisfosfonatların farmakokinetiği göz önüne alındığında, tedaviye ara verilmeden kemik yapının korunmasının yanında BRONJ'un önlenmesinin mümkün olduğu belirtilmiş ve bu doğrultuda interdisipliner hasta değerlendirilmesinin önemi vurgulanmıştır (45).

\section{Sonuç}

BRONJ oluşumu açısından risk faktörlerini değerlendirerek riskli hastaların belirlenmesi, BRONJ gelişiminin önlenmesinde ve uygun tedavinin seçilmesinde önem taşımaktadır. Invaziv dental tedavinin gerekli olduğu bisfosfonat kullanan hastalarda ve BRONJ tanısı olanlarda, bisfosfonat tedavisinin kesilmesine yönelik hastaya özgü, interdisipliner bir yaklaşım izlenerek yarar ve zarar oranları göz önünde bulundurulmalıdır.

\section{Kaynaklar}

1. Becker DJ, Kilgore ML, Morrisey MA. The societal burden of osteoporosis. Curr Rheumatol Rep 2010;12:186-91.

2. Cummings SR, Melton LJ. Epidemiology and outcomes of osteoporotic fractures. Lancet 2002;359:1761-7.

3. Sharma D, Ivanovski S, Slevin M, Hamlet S, Pop TS, Brinzaniuc $\mathrm{K}$, et al. Bisphosphonate-related osteonecrosis of jaw (BRONJ): diagnostic criteria and possible pathogenic mechanisms of an unexpected anti-angiogenic side effect. Vasc Cell. 2013;14:5-1.

4. Janovská Z. Bisphosphonate-related osteonecrosis of the jaws. A severe side effect of bisphosphonate therapy. Acta Medica (Hradec Kralove). 2012;55:111-5.

5. Kharazmi M, Persson U, Warfvinge G. Pharmacovigilance of oral bisphosphonates: adverse effects manifesting in the soft tissue of the oral cavity. J Oral Maxillofac Surg. 2012;70:2793-7.

6. Marx RE. Pamidronate (Aredia) and zoledronate (Zometa) induced avascular necrosis of the jaws: a growing epidemic. J Oral Maxillofac Surg. 2003;61:1115-7.

7. Advisory Task Force on Bisphosphonate-Related Ostenonecrosis of the Jaws, American Association of Oral and Maxillofacial Surgeons. American Association of Oral and Maxillofacial Surgeons position paper on bisphosphonate-related osteonecrosis of the jaws. J Oral Maxillofac Surg. 2007;65:369-76.

8. Colella G, Campisi G, Fusco V. American Association of Oral and Maxillofacial Surgeons position paper: Bisphosphonate-Related Osteonecrosis of the Jaws-2009 update: the need to refine the BRONJ definition. J Oral Maxillofac Surg. 2009;67:2698-9.

9. Ruggiero SL, Dodson TB, Assael LA, Landesberg R, Marx RE, Mehrotra B; American Association of Oral and Maxillofacial Surgeons. American Association of Oral and Maxillofacial Surgeons position paper on bisphosphonate-related osteonecrosis of the jaws-2009 update. J Oral Maxillofac Surg. 2009;67:2-12.

10. Ruggiero SL. Bisphosphonate-related osteonecrosis of the jaw: an overview. Ann N Y Acad Sci. 2011;1218:38-46.

11. Allen MR, Burr DB. The pathogenesis of bisphosphonate-related osteonecrosis of the jaw: so many hypotheses, so few data. J Oral Maxillofac Surg. 2009;67:61-70.

12. Coskun Benlidayi I, Guzel R. Oral bisphosphonate related osteonecrosis of the jaw: a challenging adverse effect. ISRN Rheumatol. 2013;2013:215034.

13. O'Connell JE, Ikeagwani O, Kearns GJ. A role for C-terminal cross-linking telopeptide (CTX) level to predict the development of bisphosphonate-related osteonecrosis of the jaws (BRONJ) following oral surgery? Ir J Med Sci. 2012;181:237-42.
14. Papapoulos SE. Bisphosphonates: how do they work? Best Pract Res Clin Endocrinol Metab. 2008;22:831-47.

15. Russell RG, Watts NB, Ebetino FH, Rogers MJ. Mechanisms of action of bisphosphonates: similarities and differences and their potential influence on clinical efficacy. Osteoporos Int. 2008;19:733-59.

16. Ruggiero SL, Dodson TB, Assael LA, Landesberg R, Marx RE, Mehrotra B; Task Force on Bisphosphonate-Related Osteonecrosis of the Jaws, American Association of Oral and Maxillofacial Surgeons. American Association of Oral and Maxillofacial Surgeons position paper on bisphosphonate-related osteonecrosis of the jaw - 2009 update. Aust Endod J. 2009;35:119-30.

17. Bianchi ML, Limonta C, Frasunkiewicz J, Biggioggero M, Vai S. Comment on: Bisphosphonates and osteonecrosis of the jaw. Rheumatology (Oxford). 2008;47:383-4.

18. Malmgren B, Aström E, Söderhäll S. No osteonecrosis in jaws of young patients with osteogenesis imperfecta treated with bisphosphonates. J Oral Pathol Med. 2008;37:196-200.

19. Boonyapakorn T, Schirmer I, Reichart PA, Sturm I, Massenkeil G. Bisphosphonate-induced osteonecrosis of the jaws: prospective study of 80 patients with multiple myeloma and other malignancies. Oral Oncol. 2008;44:857-69.

20. Mavrokokki T, Cheng A, Stein B, Goss A. Nature and frequency of bisphosphonate-associated osteonecrosis of the jaws in Australia. J Oral Maxillofac Surg. 2007;65:415-23.

21. Hong JW, Nam W, Cha IH, Chung SW, Choi HS, Kim KM, et al. Oral bisphosphonate-related osteonecrosis of the jaw: the first report in Asia. Osteoporos Int. 2010;21:847-53.

22. Yamazaki T, Yamori M, Yamamoto K, Saito K, Asai K, Sumi $E$, et al. Risk of osteomyelitis of the jaw induced by oral bisphosphonates in patients taking medications for osteoporosis: a hospital-based cohort study in Japan. Bone. 2012;51:882-7.

23. Sedghizadeh PP, Stanley K, Caligiuri M, Hofkes S, Lowry B, Shuler CF. Oral bisphosphonate use and the prevalence of osteonecrosis of the jaw: an institutional inquiry. J Am Dent Assoc. 2009;140:61-6.

24. Otto S, Abu-ld MH, Fedele S, Warnke PH, Becker ST, Kolk A, et al. Osteoporosis and bisphosphonates-related osteonecrosis of the jaw: not just a sporadic coincidence-a multi-centre study. J Craniomaxillofac Surg. 2011;39:272-7.

25. O'Ryan FS, Lo JC. Bisphosphonate-related osteonecrosis of the jaw in patients with oral bisphosphonate exposure: clinical course and outcomes. J Oral Maxillofac Surg. 2012;70:1844-53.

26. Diniz-Freitas M, López-Cedrún JL, Fernández-Sanromán J, GarcíaGarcía A, Fernández-Feijoo J, Diz-Dios P. Oral bisphosphonaterelated osteonecrosis of the jaws: Clinical characteristics of a series of 20 cases in Spain. Med Oral Patol Oral Cir Bucal. 2012;17:751-8.

27. Marx RE, Cillo JE Jr, Ulloa JJ. Oral bisphosphonate-induced osteonecrosis: risk factors, prediction of risk using serum CTX testing, prevention, and treatment. J Oral Maxillofac Surg. 2007;65:2397-410.

28. Manfredi M, Merigo E, Guidotti R, Meleti M, Vescovi P. Bisphosphonate-related osteonecrosis of the jaws: a case series of 25 patients affected by osteoporosis. Int J Oral Maxillofac Surg. 2011;40:277-84.

29. Palaska PK, Cartsos V, Zavras Al. Bisphosphonates and time to osteonecrosis development. Oncologist. 2009;14:1154-66.

30. Beninati F, Pruneti R, Ficarra G. Bisphosphonate-related osteonecrosis of the jaws (Bronj). Med Oral Patol Oral Cir Bucal. 2013:18;752-8

31. Villa A, Castiglioni S, Peretti A, Omodei M, Ferrieri GB, Abati S. Osteoporosis and bisphosphonate-related osteonecrosis of the jaw bone. ISRN Rheumatol. 2011;2011:654027.

32. Conte Neto N, Bastos AS, Chierici-Marcantonio RA, Marcantonio E Jr. Is rheumatoid arthritis a risk factor for oral bisphosphonate-induced osteonecrosis of the jaws? Med Hypotheses. 2011;77:905-11.

33. Yarom N, Yahalom R, Shoshani Y, Hamed W, Regev E, Elad $S$. Osteonecrosis of the jaw induced by orally administered bisphosphonates: incidence, clinical features, predisposing factors and treatment outcome. Osteoporos Int. 2007;18:1363-70.

34. Lo JC, O'Ryan FS, Gordon NP, Yang J, Hui RL, Martin D, et al. Predicting Risk of Osteonecrosis of the Jaw with Oral Bisphosphonate Exposure (PROBE) Investigators. Prevalence of osteonecrosis of the jaw in patients with oral bisphosphonate exposure. J Oral Maxillofac Surg. 2010;68:243-53. 
35. Kunchur R, Need A, Hughes T, Goss A. Clinical investigation of C-terminal cross-linking telopeptide test in prevention and management of bisphosphonate-associated osteonecrosis of the jaws. J Oral Maxillofac Surg. 2009;67:1167-73.

36. Lazarovici TS, Mesilaty-Gross S, Vered I, Pariente C, Kanety $H$, Givol N, et al. Serologic bone markers for predicting development of osteonecrosis of the jaw in patients receiving bisphosphonates. J Oral Maxillofac Surg. 2010;68:2241-7.

37. Kwon YD, Kim DY, Ohe JY, Yoo JY, Walter C. Correlation between serum C-terminal cross-linking telopeptide of type I collagen and staging of oral bisphosphonate-related osteonecrosis of the jaws. J Oral Maxillofac Surg. 2009;67:2644-8.

38. Khan AA, Sándor GK, Dore E, Morrison AD, Alsahli M, Amin F, et al. Canadian Association of Oral and Maxillofacial Surgeons. Canadian consensus practice guidelines for bisphosphonate associated osteonecrosis of the jaw. J Rheumatol. 2008;35:1391-7.

39. Hellstein JW, Adler RA, Edwards B, Jacobsen PL, Kalmar JR, Koka S, et al. American Dental Association Council on Scientific Affairs Expert Panel on Antiresorptive Agents. Managing the care of patients receiving antiresorptive therapy for prevention and treatment of osteoporosis: executive summary of recommendations from the American Dental Association Council on Scientific Affairs. J Am Dent Assoc. 2011;142:1243-51.
40. Khosla S, Burr D, Cauley J, Dempster DW, Ebeling PR, Felsenberg $D$, et al. American Society for Bone and Mineral Research. Bisphosphonate-associated osteonecrosis of the jaw: report of a task force of the American Society for Bone and Mineral Research. J Bone Miner Res. 2007;22:1479-91.

41. Department of Health, NSW, Guideline Summary. Prevention of osteonecrosis of the jaw (ONJ) in patients on bisphosphonate therapies. GL2010_010. Available from: URL: http://www0. health.nsw.gov.au/policies/gl/2010/pdf/GL2010_010.pdf. Accessed Jul 232010.

42. Ruggiero SL, Dodson TB, Assael LA, Landesberg R, Marx RE, Mehotra B. American Association of Oral and Maxillofacial Surgeons position paper on bisphosphonate-related osteonecrosis of the jaws - 2009 update. J Oral Maxillofac Surg. 2009;67:2-12.

43. Weitzman R, Sauter N, Eriksen EF, Tarassoff PG, Lacerna LV, Dias R, et al. Critical review: updated recommendations for the prevention, diagnosis, and treatment of osteonecrosis of the jaw in cancer patients-May 2006. Crit Rev Oncol Hematol. 2007;62:148-52.

44. Gallego L, Junquera L. Consequence of therapy discontinuation in bisphosphonate-associated osteonecrosis of the jaws. $\mathrm{Br} \mathrm{J}$ Oral Maxillofac Surg. 2009;47:67-8.

45. Damm DD, Jones DM. Bisphosphonate-related osteonecrosis of the jaws: a potential alternative to drug holidays. Gen Dent. 2013;61:33-8. 